\title{
SYNTHESIS AND CHARACTERIZATION OF NEW OPTICALLY ACTIVE POLY(AMIDE-IMIDE)S BASED ON $N$-TRIMELLITIMIDO-L-AMINO ACID AND TRIMETHYLENE UNITS
}

\author{
Khalil Faghihi $^{{ }^{*}}$ and Meisam Shabanian ${ }^{2}$ \\ ${ }^{1}$ Polymer Research Laboratory, Department of Chemistry, Faculty of Science, Islamic Azad \\ University, Arak Branch, Arak, Iran \\ ${ }^{2}$ Islamic Azad University, Arak Branch, Young Researchers Club, Arak, Iran
}

(Received April 9, 2010; revised September 10, 2010)

\begin{abstract}
Six new optically active poly(amide-imide)s (8a-f) were synthesized through the direct polycondensation reaction of 1,3-bis(4-aminophenoxy) propane (4) with six different derivatives of $N$ trimellitimido-L-amino acid (7a-f) in a medium consisting of $N$-methyl-2-pyrrolidone, triphenyl phosphite, calcium chloride and pyridine. The polycondensation reaction produced a series of novel poly(amide-imide)s $(\mathbf{8 a}-$ f) containing trimethylene moiety in the main chain in high yield with inherent viscosities between 0.45 and 0.80 $\mathrm{dL} / \mathrm{g}$. The resulting polymers were fully characterized by means of FTIR spectroscopy, elemental analyses, inherent viscosity, and solubility tests. Thermal properties of these polymers were investigated by thermal gravimetric analysis (TGA) and differential thermal gravimetric (DTG). All of the polymers were readily soluble in a variety of organic solvents such as $N, N^{\prime}$-dimethyl formamide (DMF), $N, N^{\prime}$-dimethyl acetamide (DMAc), dimethyl sulfoxide (DMSO) and $N$-methyl-2-pyrrolidone (NMP) at room temperature. They had $10 \%$ weight loss at a temperature above $360{ }^{\circ} \mathrm{C}$ and left $42.0-55.6 \%$ residue even at $600{ }^{\circ} \mathrm{C}$ in nitrogen.
\end{abstract}

KEY WORDS: High performance polymers, Poly(amide-imide)s, Direct polycondensation, Trimethylene moiety

\section{INTRODUCTION}

Wholly aromatic polyimides are widely used in the semiconductor and electronic packaging industry because of their outstanding thermal stability, high mechanical strength, good insulation properties with low dielectric constants, good adhesion to common substrates, and superior chemical stability $[1,2]$. However, these polymers are generally intractable and lack the properties essential for successful fabrication into useful forms because of their high melting or glass-transition temperatures and limited solubility in organic solvents. Therefore, copolyimides, such as poly(amide-imide)s and poly(acrylat-imide)s, have been developed [3-7]. Poly(amideimide)s (PAIs) are well known as a class of polymers with good compromise between thermal stability and processability. There is a growing interest in PAIs for a variety of applications as they retain good mechanical properties at high temperature when compared with other aromatic thermostable polymers. Several attempts have been made to modify the PAIs structure by introducing the functional groups or substituents capable of reducing the chain rigidity and further increasing their tractability and applicability [8-12]. Also the synthesis and application of chiral polymers is of particular interest from the viewpoint of material science and newly considered topics. Chiral polymers have found successful uses in the chromatographic separation [13-16]. In this paper the synthesis and characterization of a new series of poly(amide-imide)s (8a-f) containing trimethylene moiety in the main chain was reported by polycondensation reaction of 1,3-bis(4-aminophenoxy) propane (4) with six derivatives of $\mathrm{N}$ trimellitimido-L-amino acids (7a-f) by using triphenyl phosphite (TPP)/pyridine in the presence of calcium chloride $\left(\mathrm{CaCl}_{2}\right)$ and $N$-methyl-2-pyrrolidone (NMP).

*Corresponding author. E-mail: k-faghihi@araku.ac.ir 


\section{EXPERIMENTAL}

Materials

4-Nitrophenol (1), 1,3-dibromo propane (2), trimellitic anhydride (5), L-alanine (6a), L-valine (6b), L-leucine (6c), L-isoleucine (6d), L-phenyl alanine (6e), L-2-amino butanoic acid (6f) and triphenyl phosphite were purchased from Merck Chemical Company and used without purification. Solvents such as $N, N^{\prime}$-dimethyl formamide (DMF), $N, N^{\prime}$-dimethyl acetamide (DMAc), dimethyl sulfoxide (DMSO) and $N$-methyl-2-pyrrolidone (NMP) were purchased from Fluka Chemical Company and used without purification. Commercially available calcium chloride $\left(\mathrm{CaCl}_{2}\right)$ was dried under vacuum at $150^{\circ} \mathrm{C}$ for $6 \mathrm{~h}$.

\section{Measurements}

Fourier transform infrared (FTIR) spectra were recorded on Galaxy series FTIR 5000 spectrophotometer (England) as $\mathrm{KBr}$ pellets. Vibrational frequencies are reported in wavenumber $\left(\mathrm{cm}^{-1}\right)$. Inherent viscosities were measured by a standard procedure by using a Technico Regd Trad Merk Viscometer (Iran). Thermal gravimetric analysis (TGA and DTG) data for polymers were taken on a Mettler TA4000 System (Switzerland) under $\mathrm{N}_{2}$ atmosphere at a rate of $10{ }^{\circ} \mathrm{C} / \mathrm{min}$. Elemental analyses were measured by Vario EL equipment (Germany).

Monomer synthesis

1,3-bis(4-Aminophenoxy) propane (4) was prepared according to a typical procedure that was shown in Scheme 1 [17]. $N$-Trimellitimido-L-amino acids (7a-f) were prepared according to a typical procedure that was shown in Scheme 2 [18].

Polymer synthesis

A mixture of $(0.263 \mathrm{~g}, 1.00 \mathrm{mmol})$ of $N$-trimellitimido-L-alanine $(7 \mathbf{a}), \quad(0.254 \mathrm{~g}, 1 \mathrm{mmol})$ of 1,3-bis(4-aminophenoxy) propane (4), $2 \mathrm{~mL}$ of triphenyl phosphite, $1 \mathrm{~mL}$ of pyridine, $0.60 \mathrm{~g}$ of calcium chloride, and $5 \mathrm{~mL}$ of NMP was heated with stirring at $120{ }^{\circ} \mathrm{C}$ for $8 \mathrm{~h}$. After cooling, the reaction mixture was poured into a large amount of methanol with constant stirring, producing a stringy precipitate that was washed thoroughly with methanol and hot water, collected on a filter, and dried at $100{ }^{\circ} \mathrm{C}$ under vacuum for $12 \mathrm{~h}$. The inherent viscosity of the PAI (8a) in DMAc was $0.80 \mathrm{dL} / \mathrm{g}$, measured at a concentration $0.5 \mathrm{~g} / \mathrm{dL}$ at $25^{\circ} \mathrm{C}$.

\section{RESULTS AND DISCUSSION}

1,3-bis(4-Aminophenoxy) propane (4) was synthesized by using a two-step reaction. At first 1,3- bis(4-nitrophenoxy) propane (3) was prepared from the reaction of 4-nitrophenol (1) with 1,3-dibromoprapane (2) in $\mathrm{NaOH}$ solution. Then, the dinitro compound (3) was reduced by using $\mathrm{Na}_{2} \mathrm{~S}$ (Scheme 1). The chemical structure and purity of compounds (3) and (4) were proved with elemental analysis, ${ }^{1} \mathrm{H}-\mathrm{NMR},{ }^{13} \mathrm{C}-\mathrm{NMR}$ and FTIR spectroscopy [17].

The asymmetric diimide acids (7a-f) were synthesized by the condensation reaction of trimellitic anhydride (5) with one equimolar of L-alanine (7a), L-valine (7b), L-leucine (7c), Lisoleucine (7d), L-phenyl alanine (7e) and L-2-amino butanoic acid (7f) in an acetic acid solution (Scheme 2). The chemical structure and purity of the optically active diimide acids (7af) were proved by using elemental analysis, FTIR, and ${ }^{1} \mathrm{H}-\mathrm{NMR}$ spectroscopic techniques [19]. 


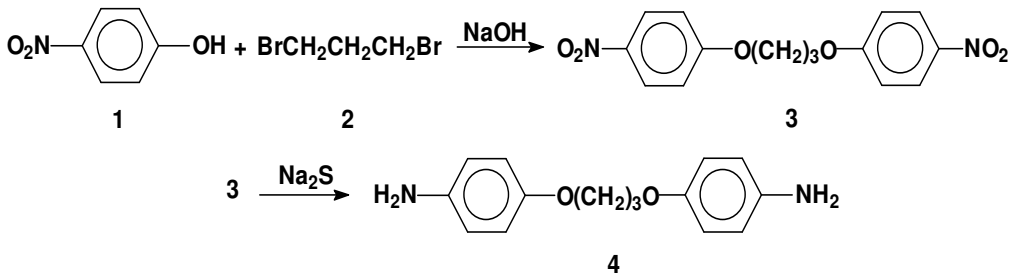

Scheme 1. Synthetic route of 1,3-bis(4-aminophenoxy) propane (4).

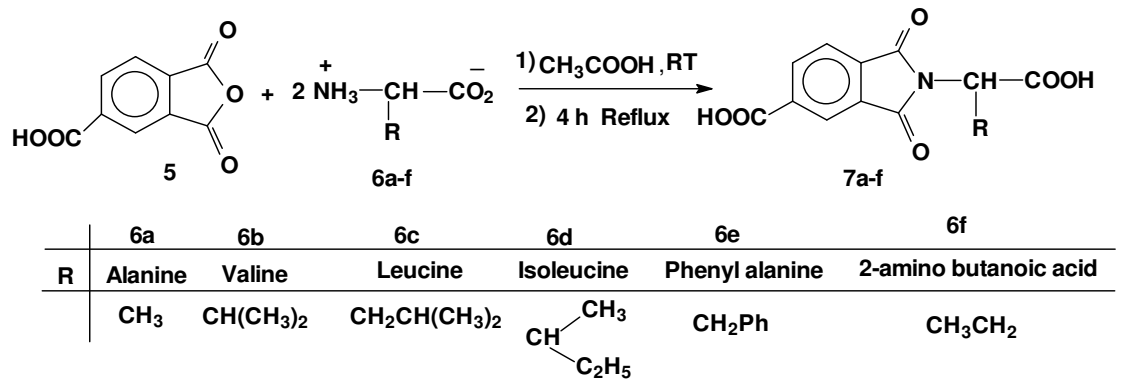

Scheme 2. Synthetic route of N-trimellitimido-L-amino acids (7a-f).

Polymer characterization

PAIs (8a-f) were synthesized by the direct polycondensation reaction of an equimolar mixture of 1,3-bis(4-aminophenoxy) propane (4) and $N$-trimellitimido-L-amino acids (7a-f) in a medium consisting of $\mathrm{N}$-methyl-2-pyrrolidone, triphenyl phosphite, calcium chloride and pyridine (Scheme 3 ). The entire polycondensation reaction readily proceeded in a homogeneous solution, tough and stringy precipitates formed when the viscous PAIs solution was obtained in good yields.

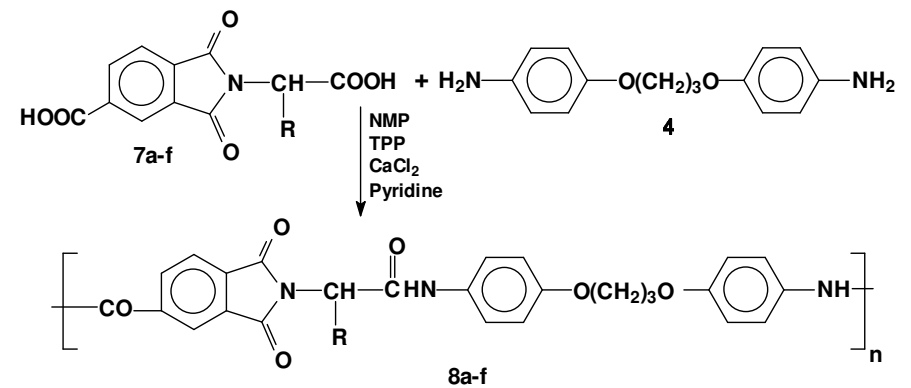

Scheme 3. Synthetic route of PAIs (8a-f).

A representative FTIR spectrum of polymer $(\mathbf{8 b})$ is shown in Figure 1. The FTIR spectrum shows the N-H stretching vibration of the amide group at $3310 \mathrm{~cm}^{-1}$ and disappearance of the $\mathrm{OH}$ stretching vibration of $\mathrm{COOH}$ groups in this polymer. The IR spectrum showed characteristic absorptions for the imide ring at around 1782 and $1720 \mathrm{~cm}^{-1}$, indicative of the asymmetric and symmetric $\mathrm{C}=\mathrm{O}$ stretching vibration, and at 1371,1090 and $720 \mathrm{~cm}^{-1}$ for imidering deformation, together with some strong absorption bands in the region of $1100-1300 \mathrm{~cm}^{-1}$ for the $\mathrm{C}-\mathrm{O}$ stretching vibration.

Bull. Chem. Soc. Ethiop. 2011, 25(1) 


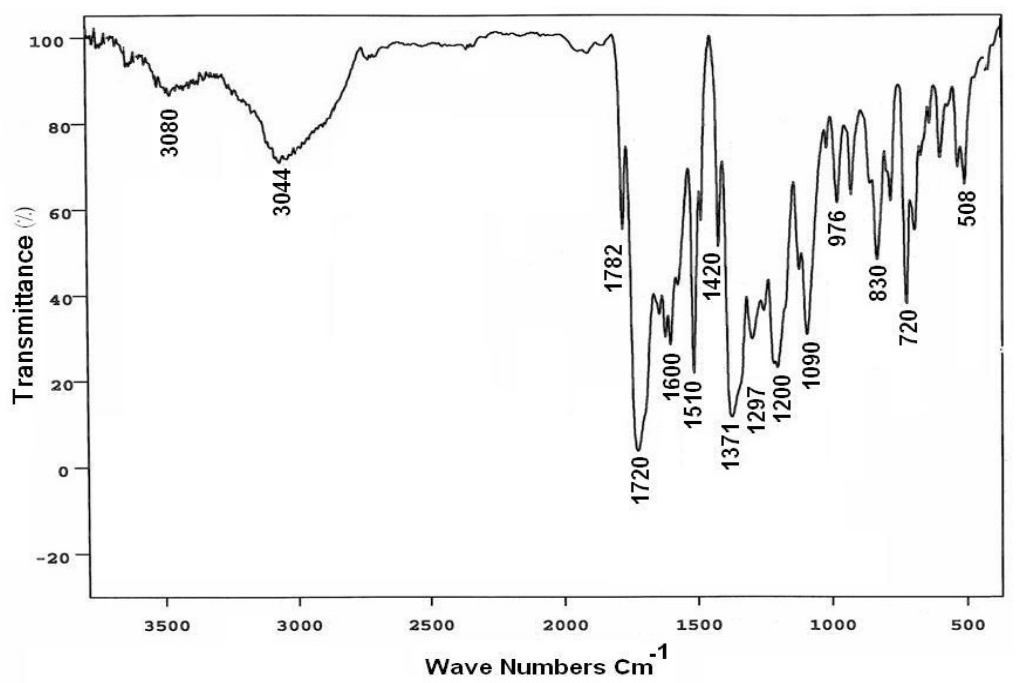

Figure 1. FTIR spectrum of PAI 8b.

The syntheses and some physical properties of PAIs (8a-f) are summarized in Table 1. These polymers had inherent viscosities around $0.45-0.80 \mathrm{dL} / \mathrm{g}$.

Table 1. Synthesis and some physical properties of PAIs ( $(\mathbf{8 a - f})$.

\begin{tabular}{|c|c|c|c|c|}
\hline Diacid & Polymer & Yield (\%) & $\eta_{\text {inh }}(\mathrm{dL} / \mathrm{g})^{\mathrm{a}}$ & {$[\alpha]_{\mathrm{D}}^{25 \mathrm{~b}}$} \\
\hline $\mathbf{7 a}$ & $\mathbf{8 a}$ & 90 & 0.80 & +84.0 \\
\hline $\mathbf{7 b}$ & $\mathbf{8 b}$ & 82 & 0.60 & +52.0 \\
\hline $\mathbf{7 c}$ & $\mathbf{8 c}$ & 90 & 0.45 & +68.0 \\
\hline $\mathbf{7 d}$ & $\mathbf{8 d}$ & 89 & 0.50 & +56.0 \\
\hline $\mathbf{7 e}$ & $\mathbf{8 e}$ & 90 & 0.60 & +79.0 \\
\hline $\mathbf{7 f}$ & $\mathbf{5 f}$ & 86 & 0.59 & +80.0 \\
\hline
\end{tabular}

${ }^{\mathrm{a}, \mathrm{b}}$ Measured at a concentration of $0.5 \mathrm{~g} / \mathrm{dL}$ in DMF at $25^{\circ} \mathrm{C}$.

The formation of PAIs (8a-f) was confirmed with elemental analysis and IR spectroscopy. The results of the elemental analyses of all the resulting polymers are listed in Table 2. The values found were in good agreement with the calculated ones for the proposed structures. These polymers were confirmed to be PAIs with FTIR spectroscopy and elemental analyses (Table 2).

The solubility behavior of these polymers was investigated with $0.01 \mathrm{~g}$ polymeric samples in $2 \mathrm{~mL}$ of solvent. All polymers were dissolved in organic solvents such as $N, N^{\prime}$-dimethyl formamide (DMF), $N, N^{\prime}$-dimethyl acetamide (DMAc), dimethyl sulfoxide (DMSO), $N$-methyl2-pyrolidone (NMP) and acetone at room temperature and are insoluble in solvents such as chloroform, methylene chloride, methanol, ethanol and water.

\section{Thermal Properties}

The thermal properties of PAIs $(\mathbf{8 a}, \mathbf{c}$ and $\mathbf{f})$ as three samples were investigated with TGA and DTG in a nitrogen atmosphere at a heating rate of $10{ }^{\circ} \mathrm{C} / \mathrm{min}$ and the thermal data are 
summarized in Table 4. The initial decomposition temperatures of 5 and $10 \%$ weight losses $\left(\mathrm{T}_{5}\right.$ and $\mathrm{T}_{10}$ ) and the char yield at $600{ }^{\circ} \mathrm{C}$ for these polymers are summarized in Table 4 . These polymers exhibit good resistance to thermal decomposition, up to $290-335{ }^{\circ} \mathrm{C}$ in nitrogen, and began to decompose gradually above that temperature. $\mathrm{T}_{5}$ for these polymers ranged from 315 to $355^{\circ} \mathrm{C}$ and $\mathrm{T}_{10}$ for all polymers ranged from 360 to $420{ }^{\circ} \mathrm{C}$, and the residual weight for these polymers at $600{ }^{\circ} \mathrm{C}$ ranged from 42.0 to $55.60 \%$ in nitrogen. Result showed that the PAI (8a) derived from L-alanine has higher thermal stability in compare to other polymers (8c and $\mathbf{8 f})$ (Figure 2). Also these results show poly(amide-imide)s (8a-f) have thermal resistance and they can be used as engineering plastic in many applications.

Table 2. Elemental analysis of PAIs (8a-f).

\begin{tabular}{|c|c|l|c|c|c|}
\hline Polymer & Formula & & $\mathrm{C} \%$ & $\mathrm{H} \%$ & $\mathrm{~N} \%$ \\
\hline $\mathbf{8 a}$ & $\mathrm{C}_{27} \mathrm{H}_{23} \mathrm{~N}_{3} \mathrm{O}_{6}$ & Calcd & 66.80 & 4.73 & 8.65 \\
& $(485.27)_{\mathrm{n}}$ & Found & 66.00 & 4.20 & 8.20 \\
\hline $\mathbf{8 b}$ & $\mathrm{C}_{29} \mathrm{H}_{27} \mathrm{~N}_{3} \mathrm{O}_{6}$ & Calcd & 67.85 & 5.26 & 8.18 \\
& $(513.29)_{\mathrm{n}}$ & Found & 67.10 & 4.90 & 7.80 \\
\hline & $\mathrm{C}_{30} \mathrm{H}_{29} \mathrm{~N}_{3} \mathrm{O}_{6}$ & Calcd & 68.32 & 5.49 & 7.96 \\
$\mathbf{8 c}$ & $(527.30)_{\mathrm{n}}$ & Found & 67.90 & 5.00 & 7.20 \\
\hline & $\mathrm{C}_{30} \mathrm{H}_{29} \mathrm{~N}_{3} \mathrm{O}_{6}$ & Calcd & 68.32 & 5.49 & 7.96 \\
$\mathbf{8 d}$ & $(527.30)_{\mathrm{n}}$ & Found & 68.00 & 4.90 & 6.80 \\
\hline $\mathbf{8 e}$ & $\mathrm{C}_{33} \mathrm{H}_{27} \mathrm{~N}_{3} \mathrm{O}_{6}$ & Calcd & 70.35 & 4.79 & 7.45 \\
& $(566.33)_{\mathrm{n}}$ & Found & 70.00 & 4.10 & 7.10 \\
\hline $\mathbf{8 f}$ & $\mathrm{C}_{28} \mathrm{H}_{25} \mathrm{~N}_{3} \mathrm{O}_{6}$ & Calcd & 67.35 & 5.00 & 8.41 \\
& $(499.28)_{\mathrm{n}}$ & Found & 66.70 & 4.40 & 7.90 \\
\hline
\end{tabular}

Table 3. Solubility behavior of PAs (8a-f).

\begin{tabular}{|c|c|c|c|c|c|c|}
\hline Solvents & $\mathbf{8 a}$ & $\mathbf{8 b}$ & $\mathbf{8 c}$ & $\mathbf{8 d}$ & $\mathbf{8 e}$ & $\mathbf{8 f}$ \\
\hline DMAc & + & + & + & + & + & + \\
\hline DMSO & + & + & + & + & + & + \\
\hline DMF & + & + & + & + & + & + \\
\hline NMP & + & + & + & + & + & + \\
\hline Acetone & + & + & + & + & + & + \\
\hline $\mathrm{CHCl}_{3}$ & - & - & - & - & - & - \\
\hline $\mathrm{EtOH}$ & - & - & - & - & - & - \\
\hline $\mathrm{MeOH}^{2} \mathrm{CH}_{2} \mathrm{Cl}$ & - & - & - & - & - & - \\
\hline $\mathrm{H}_{2} \mathrm{O}$ & - & - & - & - & - & - \\
\hline
\end{tabular}

+: Soluble at room temperature, --: Insoluble at room temperature.

Table 4. Thermal behavior of PAIs $8 \mathrm{a}, \mathrm{c}$ and $\mathrm{e}$.

\begin{tabular}{|c|c|c|c|}
\hline Polymer & $\mathrm{T}_{5}\left({ }^{\circ} \mathrm{C}\right)^{\mathrm{a}}$ & $\mathrm{T}_{10}\left({ }^{\circ} \mathrm{C}\right)^{\mathrm{b}}$ & ${\text { Char yield }(\%)^{\mathrm{c}}}^{\mathrm{c}}$ \\
\hline $\mathbf{8 a}$ & 355 & 420 & 55.6 \\
\hline $\mathbf{8 c}$ & 315 & 360 & 48.2 \\
\hline $\mathbf{8 f}$ & 340 & 400 & 42.0 \\
\hline
\end{tabular}

${ }^{\mathrm{a}, \mathrm{b}}$ Temperature at which $5 \%$ and $10 \%$ weight loss was recorded by TGA at heating rate of $10{ }^{\circ} \mathrm{C} / \mathrm{min}$ in $\mathrm{N}_{2}$, respectively. ${ }^{~}$ Percentage weight of material left undecomposed after TGA analysis $600{ }^{\circ} \mathrm{C}$. 


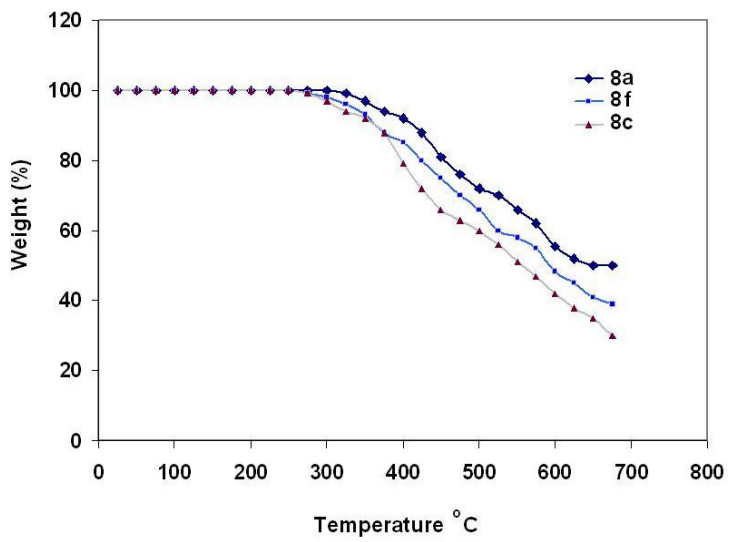

Figure 2. TGA thermograms of PAIs 8a, $\mathbf{c}$ and $\mathbf{f}$.

\section{CONCLUSIONS}

A novel series of optically active PAIs (8a-f) containing trimethylene moieties have been obtained from the direct polycondensation reaction of 1,3-bis(4-aminophenoxy) propane (4) with $N$-trimellitimido-L-amino acids (7a-f). These PAIs exhibited excellent solubility in the organic solvents at room temperature. The specific rotations of these PAIs were in the range of $[\alpha]_{\mathrm{D}}^{25}+52.0$ to +84.0 . These polymers were characterized by high solubility and good thermal stability. It was concluded that this series of polymer demonstrates a good combination of properties and processability. These characteristics indicated that optically active PAIs (8a-f) are promising materials for optical applications.

\section{REFERENCES}

1. Wilson, D.; Stenzenberger, H.D.; Hergenrother, P.M. Polyimides, Blackie: London; 1990.

2. Ghosh, M.K.; Mittal, K.L. Polyimides: Fundamentals and Applications, Marcel Dekker: New York; 1996.

3. Zhu, Y.; Zhao, P.; Cai, X.; Meng, W.D.; Qing, F.L. Polymer 2007, 48, 3116.

4. Mallakpour, S.; Kolahdoozan, M. J. Appl. Polym. Sci. 2007, 104, 1248.

5. Liaw, D.J.; Chang, F.C.; Liu, J.H.; Wang, K.L.; Faghihi, Kh.; Lee, K.R.; Lai, J.Y. J. Appl. Polym. Sci. 2007, 104, 3096.

6. Yang, C.P.; Chiang, H.C.; Chen, R.S. J. Appl. Polym. Sci. 2003, 89, 3818.

7. Wanga, Y.; Jiang, L.; Matsuura, T.; Chung, T.S.; Goh, S.H. J. Memb. Sci. 2008, 318, 217.

8. Chang, H.L.; Lin, H.L.; Wang, Y.C.; Dai, S.A.; Su, W.C.; Jeng, R.J. Polymer 2007, 48, 2046.

9. Mallakpour, S.; Rafiemanzelat, F. J. Appl. Polym. Sci. 2004, 93, 1647.

10. Tagle, L.H.; Terraza, C.A.; Leiva, A.; Yazigi, N.; Lopez, L. J. Appl. Polym. Sci. 2010, 117, 1526.

11. Hajipour, A.R.; Zahmatkesh, S.; Ruoho, A.E. Polym. Advan. Technol. 2008, 19, 1710.

12. Toiserkani, H.; Saidi, K.; Sheibani, H. J. Appl. Polym. Sci. 2009, 114, 185.

13. Ye, Q.; Wang, X.S.; Zhao, H.; Xiong, R.G. Tetrahedron: Asymmetry 2005, 16, 1595.

14. Satoh, T.; Kakuchi, T. Prog. Polym. Sci. 2004, 29, 13.

15. Lee, Y.K.; Yamashita, K.; Eto, M.; Onimura, K.; Tsutsumi, H.; Oishi, T. Polymer 2002, 43, 7539.

16. Iqbal, R.; Rizvi, S.A.A.; Akbay, C.; Shamsi, S.A. J. Chromatogr. A 2004, 1043, 291.

17. Faghihi, Kh. J. Appl. Polym. Sci. 2008, 109, 74.

18. Faghihi, Kh.; Moghanian, H. Chin. J. Polym. Sci. 2010, 28, 695.

19. Faghihi, Kh.; Feyzi, A.; Nasr Isfahani, H. Des. Monomers Polym. 2010, 13, 131. 